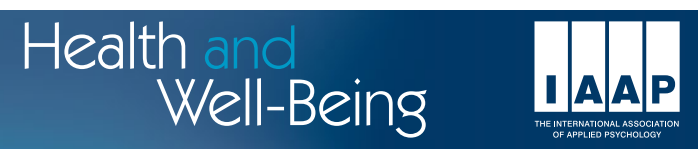

APPLIED PSYCHOLOGY: HEALTH AND WELL-BEING, 2014, 6 (3), 318-323

doi:10.1111/aphw.12030

\title{
Suicide in Happy Places Revisited: The Geographical Unit of Analysis Matters
}

\author{
Nansook Park* and Christopher Peterson \\ University of Michigan, USA
}

\begin{abstract}
Background: A recent study reported that the highest suicide rates in the US occurred in the happiest states. This is a counter-intuitive finding. The present research investigated whether the same result occurred when the unit of analysis was city. The association between happiness (of most) and suicide (by some) might differ in cities versus states because those in a city provide a more immediate influence. Methods: Suicide rates were examined in 44 large US cities as a function of the average happiness reported by residents. Results: According to our results, happier cities had lower suicide rates (Spearman's rho $=-.37$, $p<.014$ ), implying that cities may be a more meaningful unit of analysis than states for studies of suicide risk. Conclusions: The appropriate geographical unit of analysis needs to be considered seriously in psychological studies.
\end{abstract}

Keywords: cities, geography, happiness, life satisfaction, suicide

\section{INTRODUCTION}

Subjective well-being (SWB, aka "happiness") plays an important role in the health, productivity, and resilience of individuals and societies (Diener \& Chan, 2011; Lyubomirsky, King, \& Diener, 2005). Over the years, there has been growing interest in understanding contributors, correlates, and consequences of SWB across different disciplines including psychology, philosophy, medicine, political science, and economics. In recent years, researchers have advocated the use of SWB measures to guide public policies (Diener, Lucas, Schimmack, \& Helliwell, 2009; Kroll, 2011). Such measures provide information for improving the quality of life in nations that go beyond typical economic and social indicators.

A study by Daly, Oswald, Wilson, and $\mathrm{Wu}$ (2011) has received a great deal of media attention due to its documentation of a so-called "happiness-suicide paradox". They followed up an apparent global trend that the happiest countries often have high suicide rates by looking at the suicide rates across

* Address for correspondence: Nansook Park, Department of Psychology, University of Michigan, 530 Church Street, Ann Arbor, MI 48109-1043, USA. Email: nspark@umich.edu 
US states as a function of the average happiness (judged by the average self-report of their residents) in these states. The highest suicide rates occurred in the most happy states, whereas the lowest rates occurred in the least happy states. The correlation was not high (about .25, $p<.10$ ), but it was positive. They concluded that although happiness benefits the happy individual, it may put others at risk for suicide. They explained their findings in terms of social comparison. Being surrounded by happy people takes a toll on vulnerable others.

We find this argument interesting but implausible. Researchers from Durkheim to the present have linked suicide to individual unhappiness and depression and to societal disarray (Harwitz \& Ravizza, 2000). Happiness and unhappiness spread through social networks, and so too-by implication - does suicide risk (Fowler \& Christakis, 2008). It is not obvious that those in one's state provide a typical reference group (Park \& Peterson, 2010). Rather, most compare and contrast themselves to family members, friends, colleagues, and neighbors, which means that a focus on cities vis-àvis suicide risk would be more informative than a focus on states.

Evidence suggests that the geographical unit of analysis matters for understanding the effects of certain psychological variables. A study by González, Cárcaba, and Ventura (2011) examined which geographical units within Spain - region, province, or municipality (city) - accounted for the most variation in quality of life among residents. Municipalities were the most important, explaining 52 per cent of the variance versus 38 per cent for regions and only 10 per cent for provinces. A similar finding has been reported for strengths of character; meaningful differences existed across US cities but not US states (Park \& Peterson, 2010; Park, Peterson, \& Seligman, 2006).

Accordingly, we reexamined the association between happiness and suicide rates with respect to large US cities. If the Daly et al. (2011) results generalise, the association between happiness and suicide should be even stronger when the unit of analysis is the city, and we expected the association to be a negative one: Happy cities should have low suicide rates, and unhappy cities should have high suicide rates.

\section{METHOD}

An ideal research design for testing the relationship between happiness and suicide in different geographical units would be a multilevel model where US city-level data are nested within the US state-level data. Unfortunately, representative population data, both at the city and state level, for the current study do not exist.

We replicated Daly et al.'s procedure and analyses as closely as possible except for using city-level data. Our focus was the 50 largest US cities, those with populations in excess of 362,800 . 
From Benbow (2007), suicide rates per 100,000 in 2004 were available for 48 of these cities $(M=12.5, S D=5.7)$. From the Gallup-Healthways Well-Being Index (2011), happiness scores in 2010 were available for 45 of these cities. There is a time difference in data collection between suicide rates and happiness scores, which is before and after the major economic crisis in the US. This may limit the interpretation of the results.

For final analyses, data from 44 US cities that have both happiness scores and suicide rates were utilised. These scores were obtained by telephone interviews with adults from nationally representative samples of 1,000 US respondents per day throughout the year. Happiness (aka "life evaluation") was assessed by asking respondents to use a self-anchoring scale (from $0=$ the worst possible life to $10=$ the best possible life) to indicate where they saw themselves at present and where they expected to be five years in the future. Composite happiness scores were averaged within respondents from each city and weighted by demographic characteristics such as gender, age, and race to match census figures. These scores were reported as the rank order of a given US city (out of 188). To make the data interpretation more intuitive, the rank order score of happiness for each US city was reverse scored. The higher ranked city in happiness was represented by the higher rank score. For example, the happiest city was re-scored as 188 instead of 1 .

\section{RESULTS}

The highest suicide rates were for Tucson (25.0), Colorado Springs (26.1), and Las Vegas (34.5), and the lowest were for Boston (4.2), Baltimore (5.6), and Washington, DC (5.6). The happiest cities in our sample were Honolulu (\#1), Washington, DC (\#6), and Austin (\#8), and the least happy were Tulsa (\#134), Detroit (\#142), and Cleveland (\#149).

The correlation between the happiness of a city and its suicide rate was significant; Spearman's rho $=-.37, p<.014$. Because the least happy cities had the highest ranks, this negative correlation means that happy cities had low suicide rates and that unhappy cities had high suicide rates. The relationship between suicide rate and happiness in US cities is presented in Figure 1.

\section{DISCUSSION}

Our results point to a different conclusion from that of Daly et al. (2011) and are more robust. Happy cities have low suicide rates, and unhappy cities have high suicide rates. It is not clear why there is a contradiction between Daly et al.'s investigation and the current research. In both studies, assessments of suicide rates and happiness were separated in time, and happiness was assessed with large and representative surveys. Although the two investigations used different well-being measures, such measures are usually highly 


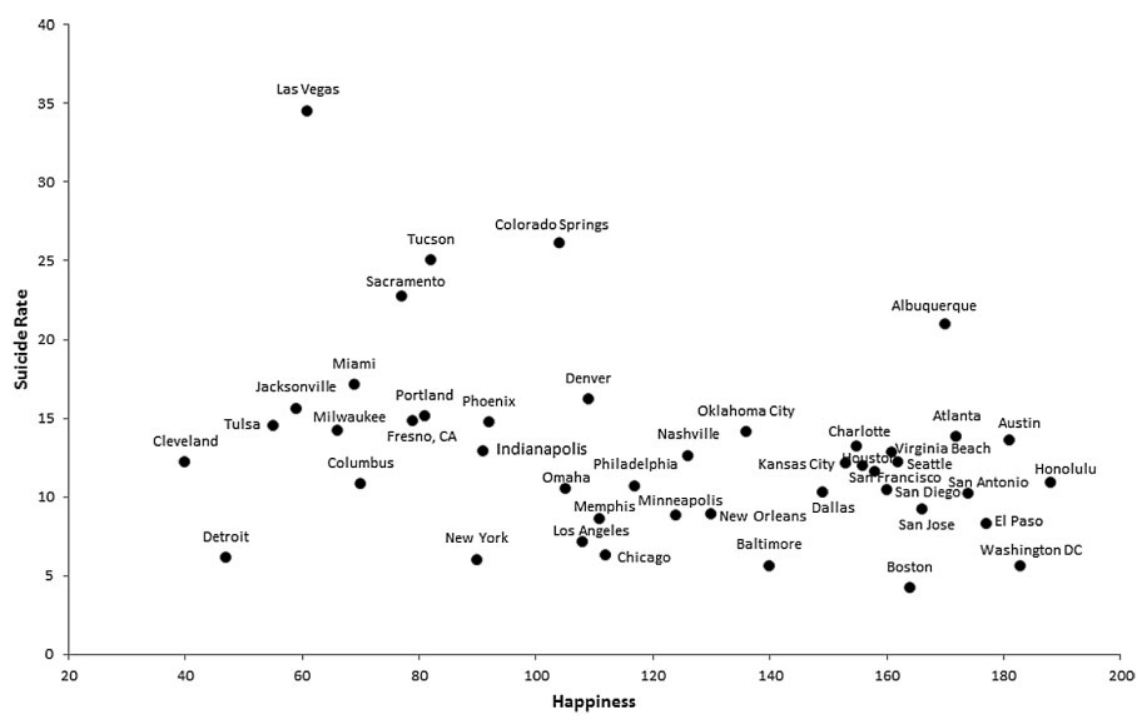

FIGURE 1. Suicide rate and happiness in US cities.

correlated at the level of individuals (Sandvik, Diener, \& Seidlitz, 1993) and one would think at the aggregate level as well.

The current findings add to the evidence that different geographical units of analysis matter. States may not always be the most appropriate unit (Park $\&$ Peterson, 2010). Grouping together all participants within a given state obscures distinctions among cities within that state. Furthermore, studies that collapse participants within states mix urban and rural residents, who differ in terms of suicide risk (Middleton, Gunnell, Frankel, Whitley, \& Dorling, 2003). Using US national data, research has consistently reported that rural residents showed significantly higher suicide mortality than urban residents (McCarthy et al., 2012; Singh \& Siahpush, 2002). Thus, for suicide studies, aggregated state-level data without consideration of rural and urban distinction could be problematic. US states may reflect important political distinctions but not always psychological ones (Seyle \& Newman, 2006).

In this context, one also has to consider the "ecological fallacy" (Robinson, 1950) which states that the relationships observed for groups based on aggregated data may not necessarily hold for individuals. This problem often occurs when the behavior of individuals must be inferred from data on aggregated sets of individuals rather than on the individuals themselves. Although the ecological fallacy, otherwise known as the cross-level inference problem, has long been described in the literatures of sociology, political science, and epidemiology (e.g. Allport, 1924; Ogburn \& Goltra, 1919), it is not commonly discussed in the field of psychology. With the increasing presence of available 
aggregated data and growing interest in ecological studies with psychological topics such as SWB, the issues of cross-level inference need to be considered carefully in order to reduce the risk of producing inconsistent results.

In this paper, we examined SWB as a risk factor for suicide at the city level. However, cultural, economic, environmental, and legal factors such as the impact of the mass media, gender role expectations, socioeconomic status, unemployment, modernisation, gun control law, and rural residency have also been known as risk factors for suicide (Stack, 2000, for a review). These factors may explain differences in suicide rates across different geographical regions. Future research considering both psychological and other factors simultaneously as risk factors for suicide would be beneficial.

The results of the present study tell a coherent story, showing that cities provide a different context from states for understanding the link between happiness and suicide. Data-informed policy decisions in the US and elsewhere are often implemented at the level of states or larger geographical units, but attention should also be paid to smaller geographical units such as cities, where the real psychological action often resides. In the future, the appropriate geographical unit of analysis needs to be considered seriously in psychological studies, and advanced methods that allow for cross-level inferences should be applied.

\section{DECLARATION OF CONFLICTING INTERESTS}

The authors declare that they have no conflicts of interest with respect to their authorship or the publication of this article.

\section{REFERENCES}

Allport, F.H. (1924). The group fallacy in relation to social science. American Journal of Sociology, 29, 688-703.

Benbow, N. (Ed.) (2007). Big cities health inventory: The health of urban America (5th edn.). Washington, DC: National Association of County and City Health Officials.

Daly, M.C., Oswald, A.J., Wilson, D., \& Wu, S. (2011). Dark contrasts: The paradox of high rates of suicide in happy places. Journal of Economic Behavior and Organization, 80, 435-442.

Diener, E., \& Chan, M.Y. (2011). Happy people live longer: Subjective well-being contributes to health and longevity. Applied Psychology: Health and Well-Being, 2, $1-43$.

Diener, E., Lucas, R., Schimmack, U., \& Helliwell, J. (2009). Well-being for public policy. New York: Oxford University Press.

Fowler, J.H., \& Christakis, N.A. (2008). Dynamic spread of happiness in a large social network: Longitudinal analysis over 20 years in the Framingham Heart Study. British Medical Journal, 338, 1-13. 
Gallup-Healthways Well-Being Index (2011). City, state, and congressional well-being reports. Document available at: http://www.well-beingindex.com/stateCongres Districtrank.asp (accessed 25 May 2011).

González, E., Cárcaba, A., \& Ventura, J. (2011). The importance of the geographic level of analysis in the assessment of the quality of life: The case of Spain. Social Indicators Research, 102, 209-228.

Harwitz, D., \& Ravizza, L. (2000). Suicide and depression. Emergency Medical Clinics of North America, 18, 263-271.

Kroll, C. (2011). Measuring progress and well-being: Achievements and challenges of a new global movement. Berlin: Friedrich Ebert Stiftung.

Lyubomirsky, S., King, L.A., \& Diener, E. (2005). The benefits of frequent positive affect: Does happiness lead to success? Psychological Bulletin, 131, 803-855.

McCarthy, J.F., Blow, F.C., Ignacio, R.V., Ilgen, M.A., Austin, K.L., \& Valenstein, M. (2012). Suicide among patients in the Veterans Affairs health system: Ruralurban differences in rates, risks, and methods. American Journal of Public Health, 102, S111-S117.

Middleton, N., Gunnell, D., Frankel, S., Whitley, E., \& Dorling. D. (2003). Urbanrural differences in suicide trends in young adults: England and Wales, 1981-1998. Social Science and Medicine, 57, 1183-1194.

Ogburn, W.F., \& Goltra, I. (1919). How women vote: A study of an election in Portland, Oregon. Political Science Quarterly, 34, 413-433.

Park, N., \& Peterson, C. (2010). Does it matter where we live? The urban psychology of character strengths. American Psychologist, 65, 535-547.

Park, N., Peterson, C., \& Seligman, M.E.P. (2006). Character strengths in fifty-four nations and the fifty US states. Journal of Positive Psychology, 1, 118-129.

Robinson, W.S. (1950). Ecological correlations and the behavior of individuals. American Sociological Review, 15, 351-357.

Sandvik, E., Diener, E., \& Seidlitz, L. (1993). Subjective well-being: The convergence and stability of self-report and non-self-report measures. Journal of Personality, $61,317-342$.

Seyle, D.C., \& Newman, M.L. (2006). A house divided? The psychology of red and blue America. American Psychologist, 61, 571-580.

Singh, G.K., \& Siahpush, M. (2002). Increasing rural-urban gradients in US suicide mortality, 1970-1997. American Journal of Public Health, 92, 1161-1167.

Stack, S. (2000). Suicide: A 15-year review of the sociological literature. Part I: Cultural and economic factors. Suicide and Life-Threatening Behavior, 30, 145162. 